\title{
Erratum
}

\section{Erratum: Hood et al., "Endoplasmic Reticulum Stress Contributes to the Loss of Newborn Hippocampal Neurons after Traumatic Brain Injury"}

In the article "Endoplasmic Reticulum Stress Contributes to the Loss of Newborn Hippocampal Neurons after Traumatic Brain Injury" by Kimberly N. Hood, Jing Zhao, John B. Redell, Michael J. Hylin, Brynn Harris, Alec Perez, Anthony N. Moore, and Pramod K. Dash, which appeared on pages 2372-2384 of the February 28, 2018 issue, funding information was inadvertently omitted by the printer. The statement of funding sources has been updated on-line to acknowledge the support of the Gilson Longenbaugh Foundation and TIRR/Mission Connect. This correction does not affect the conclusions of the paper.

DOI:10.1523/JNEUROSCI.0793-18.2018 